\title{
NOTAS SOBRE EL TEMA DE AMÉRICA EN GALDÓS
}

El tema de América no está patente en la obra de Galdós. Hay que leer con atención para encontrarlo, fuera de algunas alusiones que, en una lectura rápida, se pierden entre el cúmulo de personajes y hechos de su vasto cosmos novelesco.

El antiespañolismo franco y desdeñoso de los pueblos hispanoamericanos tras la guerra de la Independencia y la herida permanente de las guerras de Cuba produjeron en los españoles del siglo xix una inhibición casi total hacia sus antiguas colonias, traducida en desinterés e ignorancia. Era, además, el momento de la atonía nacional: de "España, país sin pulso".

No tendría, pues, nada de extraño que Galdós hubiera compartido el desinterés general. Recordemos, sin embargo, que en algunos de los españoles más conscientes, un Castelar, un Menéndez Pelayo, un Valera, un José María de Labra, empezaba a despertar la conciencia de que España no podía desentenderse de un mundo que era, en gran parte, prolongación de su propio ser y garantía de la persistencia de su propia lengua.

Por otro lado, a un observador tan minucioso y exacto como Galdós no podía escapársele el hecho de que lo americano, en una forma u otra, estaba todavía vinculado a la realidad histórica y social de España. Ni tampoco la imagen que el hombre europeo empezaba a formarse del Nuevo Mundo como tierra del futuro, campo de expansión y recreación de la cultura occidental.

$\mathrm{Y}$, en efecto, si leemos con cuidado, vemos que América está mucho más presente de lo que se cree en la novela galdosiana, aunque nadie, que sepamos, con excepción de Arturo Capdevila ${ }^{1}$, haya reparado en ello.

Nuestro propósito no es hacer un estudio a fondo, sino recoger algunas notas tomadas de las novelas y el teatro. En cuanto a los Episodios nacionales, sólo al fin han sido tenidos en cuenta por la importancia excepcional que en dos de ellos adquiere el tema.

${ }^{1}$ Cf. "Galdós en la Hispanidad", prólogo a una edición conmemorativa de La Fontana de Oro, Losada, Buenos Aires, 1943. El título de dicho prólogo indica ya su alcance y punto de enfoque. El asunto está tratado en términos muy generales, sin gran detalle. 
Ordenamos la materia en tres secciones:

1. América como parte de la realidad social española: personajes que han estado en ella, relaciones de familia, etc.;

2. América como una realidad nueva, patria de un hombre dignificado por el trabajo, el self-made man, y como un mundo donde aún le es posible al europeo fracasado rehacer su vida;

3. América como parte integrante del complejo hispánico, cuyo sentido y realidad en el pasado y en el porvenir obsesionan a Galdós en los últimos años.

Corresponden, como se verá, a las tres etapas fundamentales en la evolución del arte galdosiano señaladas por Casalduero: la naturalista, la de confrontación de materia y espíritu y la extratemporal.

\section{I}

En las novelas de la primera época -donde la visión de la realidad social se proyecta en un plano abstracto, reflejo de conflictos ideológicos- las alusiones a América son escasas, quizás convencionales, pero significativas.

De México procede la fortuna de los Lantigua, la familia de Gloria. La riqueza y el bienestar que disfrutaba don Juan, padre de la protagonista, "provenían de un tío suyo que volvió de Mazatlán (Méjico) con regular carga de pesos duros, la cual al poco tiempo soltó de sus hombros, juntamente con la de la vida, muriendo casi en el primer día de descanso" (IV, 509)2.

Y del Nuevo Mundo llega, "perdido" en el desolado paisaje de las minas de Socartes, al comienzo de Marianela, el "famoso sabio que ha corrido todo América haciendo maravillosas curas": Teodoro Golfín, que devolverá la vista a Pablo. En Golfín aparece la primera imagen del hombre enérgico y nuevo, que encontraremos más adelante. De él se nos dice que, tras de ayudar a su hermano Carlos a hacerse ingeniero, tomó el camino "que anhelaba su corazón aventurero, yéndose a América. Allá trabajó juntamente con otros afamados médicos europeos, adquiriendo bien pronto dinero y fama" (IV, 717).

América va, pues, asociada desde el principio a la aventura, al dinero, al trabajo (el emigrante que vuelve para morir en su pueblo sin poder disfrutar de su riqueza en una vida de descanso e inactividad) y también a la ciencia y el progreso.

Al entrar en la etapa realista y naturalista en la que se estudia la sociedad madrileña, esta visión un tanto conceptual da paso a otra acusadamente irónica, real y crítica. El horizonte se reduce a Cuba, parte todavía del Estado español, última colonia a la que van a parar los señoritos arruinados y con influencia para rehacer su fortuna en

${ }^{2}$ Citamos por la edición de Obras completas, Aguilar, Madrid, 1942. 
negocios sucios a base de la protección oficial, o huyendo de acreedores y, a veces, del presidio. Es decir, medio propicio para toda clase de chanchullos o refugio de perdidos.

La primera encarnación del personaje -tipo luego bastante común en las novelas contemporáneas- aparece en La familia de León Roch. Es Federico Cimarra, el marido de Pepa Fúcar. Aparte del retrato completo que de él se hace en La familia, se dice luego en El amigo Manso que era "hombre que conocen en Madrid hasta las piedras, como le conocían antes los garitos, también diputado de la mayoría, de éstos que no hablan nunca, pero que saben intrigar por setenta, y afectando independencia, andan a caza de todo negocio no limpio" (IV, 1202).

Condiscípulo de León Roch, había sido, antes de casarse con la hija del acaudalado marqués, gobernador civil y alto funcionario de Hacienda. Su suegro, para sacarlo de un mal paso, le manda a Cuba. Lejos de enmendarse en la Habana, Federico fue de mal en peor:

Bien se lo decía yo a papá [habla Pepa Fúcar]. Si aquí le comprometió en negocios disparatados y de mala fe, allá, donde parece que la distancia hace peores a los hombres... Me da vergüenza decirlo: no me puedo acostumbrar a la idea de que el autor de ciertas fechorías sea mi marido. En la Habana le fue preciso esconderse y huir, porque los corresponsales de mi padre quisieron meterle en la cárcel... (IV, 833).

Brujuleando por casas de juego, salones elegantes y medios financieros o políticos, Cimarra vuelve a aparecer en varias otras novelas - Tormento, La de Bringas, Lo prohibido, Fortunata-, y en El amigo Manso, con otros personajes de su calaña, crea la "Sociedad General para Socorro de los Inválidos de la Industria", de la que es vicepresidente.

En La familia de León Roch aparecen también por primera vez los Casa-Bojio, cubanos recién llegados a Madrid que metian "bastante ruido con la ostentación de colosal fortuna". Con una de las hijas, Susana, se casa en busca de dinero Polito Tellería, el hermano de María Egipciaca. Y en el mismo capítulo donde se nos da cuenta de estos hechos, vemos, de paso, cómo el Marqués de Fúcar obsequiaba a sus invitados con "los mejores cigarros del mundo": "Sus corresponsales de la Habana le mandaban para su uso lo mejor de lo mejor, en recompensa de la gracia y arte mágico con que se las componía para hacer fumar al país lo peor de lo peor" (IV, 912).

Tramposos o chantajistas que huyen a ultramar para escapar de presidio o rehacer su fortuna, ricas herederas que los jóvenes de la alta sociedad acosan, negocios sucios a costa de la nación. Tema e imagen de la explotación colonial que con variantes se repite en 
todas las novelas contemporáneas. Así en La desheredada, cuando Joaquín Pez - de la gran dinastía de los Peces, que se tragan con voracidad ictiológica el presupuesto- se siente arruinado, habla como única solución de irse a Cuba (IV, 1096):

Joaquín-...y por fin hemos resuelto que no tengo más remedio que irme a la Habana.

IsIDORA-iA la Habana!

Joaquín-Sí, con un destino en la Aduana, un gran destino. Es el único remedio. Los españoles tenemos esa ventaja sobre los habitantes de otras naciones. ¿Qué país tiene una Jauja tal, una isla de Cuba para remediar los desastres de sus hijos?

IsIDORA-Ya.

JoAQuín-Me iré a la perla de las Antillas, como decimos por acá. ¿Quieres ir conmigo?

A Melchor Relimpio, tras un desfalco, en lugar de mandarlo a la cárcel le nombran oficial primero de Aduanas en la capital antillana: "Parte decidido a concluir la insurrección, para lo cual no procede llevar tropas a Cuba, sino traerse a Cuba a España. Habas contadas. Él se traerá de seguro las tres cuartas partes de la Isla, o las Antillas todas, dejando vacío el Mejicano Golfo" (IV, 1076).

$\mathrm{Y}$ en La desheredada encontramos al "Excmo. Sr. (tenía la Gran Cruz) D. Alejandro Sánchez Botín”, hermano de la marquesa de Tellerías, protector de Isidora Rufete, genio de la administración y las finanzas, uno de cuyos negocios consistía en "comprar por un pedazo de pan los abonarés de los soldados de Cuba, que llegan aquí muertos de miseria, enfermos y con un papel en el bolsillo". Aparece, igual que Cimarra y otros muchos personajes galdosianos, en varias novelas. Es contertulio de Eloísa en Lo prohibido, donde se dan más detalles acerca de sus negocios y de su patriotismo (IV, 1743):

Era un vicioso, al decir de la gente; mujeriego de la peor especie... Tres veces había desempeñado en Cuba pingües destinos, y cada vez que volvía con media isla entre las uñas, repetía la sagrada fórmula: "España derramará hasta la última gota de su sangre en defensa", etc.

Y es también en Lo prohibido donde Eloísa propone a su primo y amante José María que se haga "amigo, muy amigo de los ministros, para ver si cae un empréstito de Cuba, ya que en la Península no se hacen ahora". Tras de lo cual comenta (IV, 1759):

Esa isla de Cuba es todavía, aun de capa caída como está, una verdadera mina que no se explota bien. ¡Ah! se me ocurre ahora que lo que debe hacer España es venderla. Y mira, nadie mejor que tú se podría encargar de las negociaciones en los Estados Unidos, en Alemania o en el Infierno. Con que te dieran el medio por ciento de corretaje... 
Idénticos motivos de crítica a la venalidad e inconsciencia de que daba muestras la sociedad de la capital española ante los últimos restos de su imperio colonial se reflejan en otros personajes como Pedro Minio, en La de Bringas; Aguado, "el Catón Ultramarino", en La Incógnita; José Antonio Urrea, en Halma; o en el amante de Amparo Sánchez Emperador, en Tormento, el sacerdote Pedro Polo, que, arrepentido, acepta un curato en Filipinas (prolongación de lo americano).

Filipinas, en efecto, está en un plano análogo al de Cuba, aunque las alusiones sean mucho menos numerosas. Irónicamente se asocian en el retrato de Pedro Minio, padre, Marqués de Santa Bárbara, insigne general que no había ganado más que "batallas cortesanas en las antecámaras palatinas..., que pasará a la posteridad por los célebres dichos de la espada de Demóstenes, la tela de Pentecostés y el alma de Garibaldi y por aquello de ir a la Habana haciendo escala en Filipinas" (IV, 1590).

Por América habían andado también don Evaristo Feijóo, el protector de Fortunata, el desgraciado burócrata Ramón de Villaamil, Ramses II, protagonista de Miau, y varios miembros de la familia de los Babeles: el pintoresco Don Pito, tío de Dulcenombre, la amante de Ángel Guerra, y también Arístides, que a causa de un desfalco en Cuba tuvo que huir y fue a parar a Costa Rica, donde fundó un periódico e hizo imprimir unas tarjetas que decían "Arístides García Babelli, Barón de Lancaster".

Junto a estos personajes relacionados con Cuba, en forma casi siempre alusiva e incidental, hay una proyección más detallada de lo cubano, en la persona y en la familia de José María Manso, el hermano de Máximo. Representa José María al emigrante enriquecido que vuelve a la madre patria a figurar y a hacer carrera política. Y en contraste con la ironía acerada, cáustica, que tienen casi todas las alusiones que hemos recogido, resalta la viva simpatía, el humor comprensivo que Galdós pone al hablar de la familia criolla: la niña Chucha (Doña Jesusa), suegra de Manso, la cuñada Chita (Merceditas) y Lica, la mujer, o el criado Rupertico, negrito de catorce años, que formaba parte del séquito tropical juntamente con una mulatica, un loro, y dos tomeguines.

Al hablar de la suegra, nos hace sentir el narrador la soledad que se apodera de la vieja cubana en el clima, para ella extraño física y moralmente, de Madrid:

... la niña Chucha, atacada de súbita nostalgia, pedía con lamentos elegíacos que la llevasen a su querida Sagua, porque se moría en Madrid de pena y frío...

¡Pobre doña Jesusa, y qué lástima me daba! Su única distracción era contarme cosas de su bendita tierra, explicarme cómo se hace el ajiaco, describirme los bailes de los negros y el tañido de la 
maruga y el güiro, y por poco me enseña a tocar el birimbao. No salía a la calle por temor a encontrarse con una pulmonía; no se movía de su butaca ni para comer (IV, 1196).

Lica está tratada con honda comprensión en toda la novela, pese a algunos trazos burlones. Alma inocente, se entiende bien con el narrador, el inocente "amigo Manso". Y en ella hace encarnar Galdós el mito romántico de la América virginal, primitiva e ingenua:

Lica (que este nombre daban a mi hermana política) traía un vestido verde y rosa, y el de su hermana era azul, con sombrero pajizo. Ambas representaban, a mi parecer, emblemáticamente la flora de aquellos risueños países, el encanto de sus bosques poblados de lindísimos pajarracos y de insectos vestidos con todos los colores del iris... (IV, 1193-1194).

Lica era una criatura celeste, un corazón seráfico. No conocía el mal; ignoraba cuanto de falaz y malicioso encierra el mundo, y a los demás medía por la tasa de su propia inocencia y bondad. . (ibid., 1199).

$\mathrm{Y}$ tanta era la inocencia de la guajirita que no se desazonaba por hacer a veces ridículo papel, o no caía en ello (ibid., 1200).

Aunque se trate de toques ocasionales y personajes episódicos, la insistencia en pintar la irresponsabilidad de la sociedad madrileña, encanallada o inhibida, muestra claramente cómo veía Galdós el problema de Cuba. Nadie en la abundante y profusa literatura del desastre denunció con mayor penetración la actitud de la metrópoli. Si a ello se añade el contraste con la familia de José María Manso, es manifiesta la simpatía hacia los criollos.

Aun dentro del período más plenamente realista -el de las primeras novelas contemporáneas-, siempre encontramos en la obra de Galdós imaginación creadora y un elemento ideológico. Éste, el que ahora nos interesa, suele tomar la forma de la oposición, atracción y síntesis de los contrarios. Vago reflejo de las concepciones dialécticas de la historia en la filosofía del siglo xIx, con influjos más o menos directos de Hegel y de Comte. Juego de pasado y presente, materia y espíritu, decadencia y regeneración. En este plano, el tema de América se presenta como la tierra de un hombre nuevo: el emigrante o indiano, de personalidad vigorosa, capaz de crearse su propio destino y de influir en el destino de los demás, posible agente de renovación en una sociedad desvitalizada como la española. Lo que en Teodoro Golfín era casi una abstracción -sus viajes por América- va a tomar fuerza, sentido e individualidad poderosa en los personajes a que nos vamos a referir, pertenecientes a las obras de plenitud. 
El primero es Agustín Caballero, en Tormento. Ha vivido en América, en Bronxville, frontera de Texas. Cansado de soledad y de lucha vuelve a España, no a figurar en la sociedad madrileña como José María Manso, sino en busca del calor de la familia y de una vida de orden. Llega con dinero, y también con "el color de América, tinte de fiebre y fatiga en las ardientes humedades del Golfo Mejicano, la insignia o marca del apostolado colonizador, que con la vida y la salud de tantos nobles obreros, labra las potentes civilizaciones del mundo hispanoamericano".

Es, pues, el nuevo colonizador, muy distinto del conquistador antiguo. En el Madrid de la trampa y las falsas pretensiones, la presunción y la indolencia, se siente totalmente desplazado: "En verdad aquel hombre que había prestado a la civilización de América servicios positivos, si no brillantes, era tosco y desmañado, y parecía muy fuera de lugar en una capital burocrática donde hay personas que han hecho brillantes carreras por saber hacerse el lazo de la corbata" (IV, 1475).

Ya desde el principio, cuando el criado, Felipe Centeno, corrige la falsa impresión que en Ido del Sagrario produce la opulencia del indiano, se establece la oposición con la aristocracia madrileña: “-¡Si mi amo no es Marqués!... Mi amo es don Agustín Caballero..."

Cae Agustín en el mundo voraz de sus primos, los de Bringas, donde se le explota. Al fin encuentra salvación en el amor de Amparo Sánchez Emperador. Y cuando se entera de su deshonra, de sus amores con el capellán Pedro Polo, se sobrepone al escándalo y se va a Francia con ella. (Tema de la huída de que volveremos a hallar otros ejemplos).

Este nuevo caballero se ha liberado, por el trabajo y por el dinero, de la esclavitud a los prejuicios sociales y del falso honor que carcomen a la sociedad española en su atonía. Agustín se crea su propia moral, y con ella, redime a Amparo.

Casalduero (Vida y obra..., p. 79) ha visto muy bien, al estudiar "el carácter nacional" en la obra de Galdós, la significación del personaje y del triángulo Polo-Amparo-Agustín:

Amparo Sánchez Emperador es una buena muchacha y a la vez España - con el Imperio tras el Sánchez-, que arrastrada a la indignidad y la miseria por el sacerdote Polo Cortés, es salvada por Agustín Caballero -el primer apellido es Caballero-, hombre pobre, que consigue una fortuna gracias a su esfuerzo y trabajo, y que tiene todavía la fuerza de carácter para despreciar los prejuicios sociales. Este Agustín Caballero no es el caballero calderoniano, sino su opuesto, el pícaro redimido, el caballero naturalista. Mientras los héroes calderonianos han degenerado en unos Polo Cortés, capaces sólo de soñar que no son lo que son, conquistando imperios con la imaginación únicamente, causando de paso la ruina de Es- 
paña, el picaro ennoblecido por el trabajo es el verdadero caballero que puede salvar y salva a España de la degradación en que la han hecho caer.

A nosotros nos interesa destacar la condición de hombre hecho en América, que no es puramente circunstancial.

Forma todavía más inequívoca tiene el tema en el caso de José Cruz, el Pepet de La loca de la casa, obra de claras inferencias en cuanto a la oposición y armonía de pasado y presente, de materia y espíritu y de conciliación de clases sociales, que hemos estudiado en otro lugar ${ }^{3}$. Aquí nos limitaremos a señalar el perfil del personaje y su choque con el mundo español al que regresa.

Hombre humilde y rudo, antiguo criado de los Moncada, emigró a Mazatlán e hizo inmensa fortuna trabajando en las minas de California. Huguet le llama "el Californiano". Viene a conquistar el mundo que le despreció por su pobreza, a adueñarse de la familia de sus antiguos amos, redimiéndola de la ruina. Viene, declara, "a ser señor donde fui criado", "a hacer una revolución". Su tosquedad sólo encuentra, al principio, incomprensión y burla. Para Gabriela Moneada es "de los que van cerriles a América y luego vuelven cargados de dinero"; y para Jaime: "la riqueza en perfecto consorcio con la barbarie". He aquí el credo de Cruz:

-Como me he formado en la soledad, sin que nadie me compadeciera, adquiriendo todas las cosas por ruda conquista, brazo a brazo, a estilo de los primeros pueblos del mundo, hállome amasado con la sangre del egoísmo, de aquel egoísmo que echó los cimientos de la riqueza y de la civilización...

Digo que la compasión, según yo lo he visto, aquí principalmente, desmoraliza a la humanidad y le quita el vigor para las grandes luchas con la Naturaleza. De ahí viene, no lo duden, este sentimentalismo, que todo lo agosta, el incumplimiento de las leyes, el perdón de los criminales, la elevación de los tontos, el poder inmenso de la influencia personal, la vagancia, el esperarlo todo de la amistad, y las recomendaciones, la falta de puntualidad en el comercio, la insolvencia... Por esto no hay ley, ni crédito; por eso no hay trabajo, ni vida, ni nada... Claro, ustedes, habituados ya a esta relajación, hechos a lloriquear por el prójimo, no ven las verdaderas causas del acabamiento de la raza, y todo lo resuelven con limosnas, aumentando cada día el número de mendigos, de vagos y de trapisondistas (acto I, esc. vu; V, 1669).

Como se sabe, Cruz, "el monstruo", termina siendo domeñado por la espiritualidad de Victoria ("la loca de la casa"), no sin que ésta se someta, a su vez, a la poderosa voluntad de su marido. La vieja

${ }^{3}$ Cf. "La significación de La loca de la casa", CuA, 4 (1945), núm. 3, pp. 237-268, y en mis Estudios galdosianos. 
familia de aristócratas industriales se salva de la bancarrota y el dinero de Cruz se pone al servicio de valores sociales y espirituales.

De Cuba hemos pasado a la frontera de Tejas y California en los Estados Unidos. No nos parece casual el que tanto Agustín como Cruz, "héroes americanos" (ejemplos del "hombre naturalista", según Casalduero), se hayan formado y hayan conseguido la riqueza en territorios que fueron de España y dejaron de serlo: en la frontera donde el mundo español que, agotado, dejó esas tierras casi yermas, se encuentra con el utilitarismo moderno, el positivismo que Galdós no rechazaba, pero creía insuficiente.

Tampoco es casual que del Madrid burocrático y picaresco de las novelas se haya pasado en La loca de la casa al ambiente industrial de Cataluña, donde la aristocracia empezaba, sin renunciar por entero a sus prejuicios, a entrar en el mundo capitalista y a aceptar sus responsabilidades sociales.

La fórmula del dinero de América como puente de redención se repite -igual que otras fórmulas galdosianas- a partir de La loca de la casa. Otro ejemplo sería el desenlace de El tacaño Salomón, donde la fortuna, procedente de las andanzas del protagonista y de Jacobo Mendrugo por la Argentina, se pondrá "al servicio del pueblo indigente".

Complemento de esta idea será, también en el teatro, la visión del Nuevo Mundo como campo en el que pueden rehacer su vida los fracasados, los perseguidos o los jóvenes sin esperanza en el estancamiento de la existencia española. Patria del futuro y del progreso frente a una patria que se hunde, agotada y dividida.

Es la solución que, como alternativa del suicidio, Cruz propone a Daniel, hijo de la Marquesa de Malavella. Daniel -como Victoria- había querido consagrarse al misticismo, para caer luego en la desesperación.

Gruz-Que vuelva usted a la vida ordinaria, que trabaje.

DANIEL-_Vivir, trabajar! ¿Qué significa eso?

Cruz-Vaya usted a América.

Daniel-No me queda duda: es el demonio, el espíritu tentador, astuto, fuerte, lógico... ¿Pero cómo, Dios mío, me sugiere la idea salvadora?. . Porque si... me salvaré. .. América, vida. .., mar. .. , tierras lejanas, sí, sí (acto IV, esc. x; V, 1713).

Daniel se queda en España pero la idea resurge, en forma aún más explícita, en La de San Quintin. Víctor, el pueblo, el hijo natural, dotado de inteligencia y voluntad, y Rosario, Duquesa de San Quintín, aristócrata empobrecida -que, como Victoria, representa el espíritu, el amor y la comprensión ante la ruina, las intrigas y los 
prejuicios comunes a la aristocracia y a la burguesía acaudalada (los Buendia)-, se van, cara al porvenir, "a una comarca industrial del Estado de Pensilvania":

RUFINA-iSe van para siempre!

Víctor-iA la mar, a un mundo nuevo!

Rosario y Víctor (al unísono, con voz clara y vigorosa) -¡Adiós!

DON CÉSAR-Se van... Es un mundo que muere.

Don José-No, hijos míos, es un mundo que nace. (Telón). (Esc. final; IV, 718).

Con el de la atracción y significado de América se enlazan aquí otros dos temas favoritos de Galdós en esta etapa de su obra: el de la conciliación de aristocracia y pueblo, cuyo sentido - muy obvio por otro lado- él mismo explica en el prólogo de Alma y vida; y el de la huída o destierro voluntario. Observemos de paso que la acción de La de San Quintín se sitúa en una ciudad convencional del mismo nombre que la de Gloria: Ficóbriga. Y sería interesante, si entrase en nuestro propósito, trazar las diferencias entre la novela de la intolerancia religiosa, escrita al comienzo de su carrera, y el teatro de conflictos sociales e históricos.

El destierro voluntario de la pareja joven va unido en Galdós a su desengaño ante las posibilidades de una España liberal. Se ha ido dando cuenta de que España está dividida por dos fanatismos irreconciliables, monstruo de dos cabezas. Por eso, en La fiera -drama escrito en 1896 , el mismo año de la dramatización de Doña Perfecta, y dos después de La de San Quintin- el héroe, Berenguer, antes de huir con la aristócrata Susana, Baronesa de Celis, mata a Juan, personificación del fanatismo absolutista, y a San Valerio, personificación del fanatismo liberal:

Berenguer (delirante, mirando a uno y otro cadáver)-Sí; he matado a la fiera. ;Muertos los dos!

Susana-Huyamos a regiones de paz.

BERENGuer-Huyamos, sí; que éstos... éstos resucitan.

La acción de La fiera se sitúa en ${ }_{1822}$, en el ambiente de la Regencia de Urgel, antecedente del carlismo y primer brote de la guerra civil. Lo que Galdós ha visto justamente es la resurrección repetida de los dos fanatismos. Su visión desesperanzada y pesimista se vierte en las dos últimas series de los Episodios nacionales. Ya en La Revolución de Julio (cuarto de la $4^{\mathrm{a}}$ serie) se lee: "Mis ilusiones de ver a España en camino de su grandeza y bienestar han caído y son llevadas por el viento. No espero nada, no creo nada". Palabras que anuncian las del final de Cánovas, último de los Episodios. La Madre, Clío, musa de la Historia, dice: "Alarmante es la palabra revolución. Pero si no inventáis otra menos aterradora, no tendréis 
más remedio que usarla los que no queráis morir de la honda caquexia que invade el cansado cuerpo de la nación".

Observó Casalduero cómo, tras su gran época de novelador de la realidad, e influido ya en su vejez por Unamuno y Ganivet, pasa Galdós de la interpretación de los hechos históricos que narra a "querer descubrir el ser español, el alma española, saber ¿qué es Espa$\tilde{n} a$ ?" La observación es justísima y fina, aunque cabe pensar que Galdós podría haber coincidido con sus discípulos (en él aprendieron mucho sin duda los autores de Paz en la guerra y de Pío Cid) por evolución propia. Hay, sin embargo, rasgos de estilo, apuntados también por Casalduero, que apoyan su opinión. Digamos, en otros términos, que Galdós pasa de hacer historia novelada a buscar el sentido de la Historia o de la "intra-historia"'. Aquí vamos a encontrar la última dimensión, y para nosotros la de mayor interés, del tema de América con toda su trascendencia histórica.

\section{III}

En la cuarta y quinta series de los Episodios (escritas entre 1902 y 1912) se ve que Galdós ha abandonado toda esperanza sobre el presente y sobre las posibilidades de regeneración nacional (recordemos dos títulos: La de los tristes destinos, último de la $4^{2}$ serie, y España trágica, segundo de la $5^{\mathrm{a}}$ ). Narra las repetidas crisis que van del $4^{8}$ a la Regencia. Y ante los repetidos fracasos se vuelve hacia el pasado, en busca de los valores extratemporales históricos que constituyen el ser de España o, por mejor decir, de lo hispánico, aunque la palabra resulte anacrónica y equívoca. Va por caminos paralelos a los del noventa y ocho. $\mathrm{Y}$ antes de que los escritores de ese momento abandonen su crítica pesimista, llega él, sin falsear la realidad histórica que sigue siendo su tema, a "la afirmación española". Digamos, de paso, que éste es el título de un libro antinoventaiochista de Salaverría que Galdós prologa.

Es entonces cuando empieza a meditar sobre lo americano, descubriendo profundamente su significación. Ésta se apoya en tres ideas complementarias: condenación de los rebrotes de imperialismo; comunidad profunda de sentimiento y espíritu entre españoles e hispanoamericanos, por encima de sus diferencias; España, como entidad histórica creadora, pertenece al pasado, América al porvenir.

Ideas que forman la trama simbólico-ideológica, novelesca, de dos episodios: La vuelta al mundo en la "Numancia" (de ambiente y tema casi exclusivamente americanos), y Prim, ambos escritos en 1906. Examinemos primero éste, por presentarse en él el tema en for-

${ }^{4}$ Sobre este tema, además de Casalduero, puede verse Carlos Clavería, "El pensamiento histórico de Galdós", $R N C, 19$ (1957), núms. 121/122, pp. $170-177$. 
ma más restringida y por referirse a acontecimientos anteriores: la expedición a México en 1862.

Los nuevos sueños imperiales -el querer hacer papel de gran potencia- eran para Galdós vanas empresas quijotescas o algo peor: fuente de negocios turbios, distracción y engaño para que no se viera el verdadero estado del país, o lamentable imitación del neoimperialismo napoleónico francés. Por ello condena igualmente la intervención en Portugal del 47 , la expedición a Roma para auxiliar a Pío IX, la anexión de Santo Domingo y la guerra de África. Como Costa, pensaba que había que echar doble llave al sepulcro del Cid, y como Ganivet, que "in interiore Hispaniae habitat veritas", aunque sin las ilusiones del granadino.

En Prim el pensamiento galdosiano está expuesto con toda claridad, en una forma real y simbólica tan evidente que hoy nos deja la impresión, errónea por supuesto, de una gran ingenuidad artística.

Santiaguito Ibero, joven de dieciocho años, se había recalentado el cerebro con la lectura de gloriosas empresas; llegó a encendérsele "hasta el rojo con las increíbles hazañas de Hernán Cortés, y de ensueño en ensueño o de locura en locura acabó por la de querer imitarlas o reproducirlas en nuestro tiempo". "Clavóse esta idea en el pensamiento de Iberito y su orgullo la remachó. Los extraños sucesos de la Conquista le fueron tan familiares como si los hubiese visto..."

Ante la expedición que Isabel II prepara al mando de Prim, piensa Iberito:

Es mi deber presentarme al general Prim y pedirle que me lleve como soldado a la conquista de Méjico...

Su destino, que hasta entonces había sido un oscuro acertijo, estaba ya bien claro. Dios y la Naturaleza murmuraban en su oído: "Corre; no te detengas... ¿No ves al término de España una llanura sin fin entre azul y verde? Es el océano. ¿No distingues de la otra parte nuevas tierras? Es la inocente América. ¿Ves una figura de matrona que en las rocas traza inseguras rayas con un punzón?... Es la Historia" (III, 539).

Como un nuevo Quijote, el joven, "llegada la noche..., por la puerta falsa del corral salió a un campo que no era el de Montiel, pero sí pariente suyo". En su viaje a Madrid a través de la sierra y los páramos de Soria (la bronca Celtiberia donde la historia se ha parado), va a dar a un mesón de Almazán. Allí unos "bárbaros", trajinantes y labradores - jugadores de mus-, comentan con escepticismo: En Madrid todos eran unos pillos de la Reina para abajo; O'Donnell, "un tal y un cual que estaba compinchado con la Patrocinio... La guerra de África no había sido más que un engañabobos. . . La expedición a Méjico que le estaban preparando no era más que un arbitrio para traerse de allá una millonada de pesos duros". 
Iberito desafía, a la manera caballeresca, a aquellos salvajes después de afirmar que "a Méjico no va don Juan Prim para negocio suyo, sino de la nación, porque va para conquistarnos otra vez a la Nueva España" (ibid., 541-542).

El entusiasta adolescente, nuevo conquistador, no logra ver realizados sus sueños heroicos; y el general español -esperanza por aquellos años de salvación de la patria- tuvo el buen acuerdo de retirarse "con sus tropas a Veracruz, no pensando más que en embarcarlas para volver a España; y como no tuviese buques especiales a mano, embarcó en los ingleses, y a casa, es decir, a la Habana”.

Así acabó lo que el narrador llama "el delirio de Prim y de América".

En forma mucho más compleja, profunda y abarcadora están vistas las relaciones de los dos continentes, los lazos y diferencias entre españoles y americanos en La vuelta al mundo en la "Numancia”. Es el tema central, único, de la obra. Y es sorprendente que nadie la haya leído con la atención que merece. Un comentario detenido exigiría más espacio del que disponemos. Trataremos de dar una idea rápida de sus varias sugerencias.

Se basa en la guerra llamada del Pacífico, con los bombardeos de Valparaíso y el Callao en 1866. El héroe novelesco es Diego Ansúrez, celtíbero y navegante. En su juventud había servido en la Armada. "Tres veces fue a las Antillas, corrió toda la mar Caribe y, por fin, en la expedición científica al Pacífico pasó de ida y de vuelta el temeroso estrecho de Magallanes". Retirado, se dedica al comercio de cabotaje. Un día, por tierras de Valencia, se encuentra con una monja que se fuga del convento. Era granadina, se llamaba Angustias. Y Ansúrez, cuando decide unirse a ella, la rebautiza con el nombre de Esperanza. De esta unión nace una hija, Marina o Mara. Muerta la madre, padre e hija topan por un camino, cerca de Motril, con un desastrado caminante. Es el peruano Belisario Chacón, joven, poeta, rebelde y aventurero. El americano les da noticia de su vida (III, 455):

Había nacido al pie de los Andes; sus primeros pasos los dio sobre pavimentos de barras de plata. Su padre era español, que cruzó los mares y se fue en busca de la madre gallega, que así llaman allí a la fortuna. Casó con una limeña muy guapa...

De la dureza del padre y de la propensión del hijo a la independencia, resultaron castigos, rebeldías y sucesos lamentables...

Terminó escapándose y tras muchas aventuras había ido a dar a España. Se prenda de Mara, la corteja "en prosa y verso". Se la pide a Ansúrez, el cual no quiere dar su hija a un "coplero". Y Belisario afirma que Mara "sería suya, quisiéralo o no el señor Ansúrez, porque la ley del amor, más alta y fuerte que todos los respetos 
humanos, había de cumplirse" (ibid., 458). Mara se fuga con el poeta. Es “arrebatada por el gavilán americano".

Ansúrez se arruina, y en su fracaso y soledad decide volver al servicio y se embarca en la fragata Numancia. Allí por boca del maquinista Fenelón, mitad francés y mitad catalán, conoce los detalles del rapto de su hija; se entera también de que Belisario, el poeta, era riquísimo. Y Fenelón, que dará todas las claves interpretativas, bastante evidentes por otra parte, expone la tesis del romanticismo hispanoamericano:

Pues.. Belisario no habló a usted de intereses -repuso Fenelón- porque es lo que llamamos un romántico. . ¿ ¿Se entera usted? Porque llevando las cosas por derecho y obteniendo la mano de la niña según el estilo corriente, no resultaba poesía. . Lo poético era meterse por el camino más largo y más difícil, manteniendo la ilusión, que es la salsa de que se alimentan las almas románticas.

Mara era asimismo "una romántica de marca mayor": "romántica vino al mundo; el aire andaluz agravó lo que bien puede llamarse enfermedad, y las lecciones de las monjitas acabaron de rematarla..."

El que no es romántico es Fenelón, en quien volvemos a encontrar el sentido del dinero, del positivismo que Galdós aceptaba: "Yo, así por el lado catalán como por el lado francés, soy esencialmente práctico y positivista... Yo no desprecio el dinero, no lo llamo vil, no lo tengo por prosa, sino por la más alta poesía" (ibid., 463 ).

Mientras navegan rumbo a América, el pobre celtíbero medita. "Ansúrez no cesó de cavilar en su asunto; y revolviéndolo y mirándolo por todas sus caras, trataba de reconstruir el rapto de su hija para convertirlo de novela en historia" (466).

El subrayado es nuestro. Novela e historia se confunden en el resto del Episodio, que ocurre ya en tierras y costas americanas. Sería largo detenerse en su análisis.

Hay una bella descripción de Lima. Belisario y Mara andan por El Cuzco y Arequipa. Asistimos a los bombardeos. Se habla de las revoluciones americanas "que se parecen a las nuestras - dice el narrador- como una castaña nueva a una castaña pilonga", y la pugna entre los generales Pezet y Canseco por la presidencia tiene el mismo carácter quijotesco que las aspiraciones guerreras de la metrópoli:

Mientras los dos caudillos se iban acercando con parsimonia, y alzaban las cortadoras espadas queriendo renovar la pelea entre Don Quijote y el Vizcaíno, los pueblos se amotinaban aprovechando la debilidad de las guarniciones y el desequilibrio de aquellas autoridades tambaleantes, que tenían un pie en la legalidad y pie y medio en la rebeldía (499). 
Personaje importante es el español Mendaro, antiguo compañero de Ansúrez, establecido en Lima donde tiene una pulpería, mujer y familia peruana. Es el nuevo criollo. Mendaro explica las causas de la guerra:

Todo este torbellino - decía Mendaro- ha venido, ¿sabes de qué? Pues de añejos piques y desavenencias entre peruanos y españoles; del pleito viejo por si reconocemos o no reconocemos la independencia del Perú..., del mal trato que aquí dieron a unos catalanes y valencianos..., de bofetadas, palos y mojicones que han llovido en la tierra donde no llueve agua..., de que España se metió en Santo Domingo y quiso meterse en Méjico..., de una gravísima trapatiesta que hubo en Talambo, peruanos ofendidos, españoles muertos..., de que en Chile atropellaron a unos vizcaínos..., de las muchísimas desverguienzas que escriben aquí los periódicos, y, en fin, de que los gobiernos de una banda y otra están dejados de la mano de Dios... Allá se les subió a la cabeza el humo de la guerra de África, y acá tienen los humos de su republicanismo y el no ser menos que la vecina de abajo, Chile, y que las vecinas de arriba, Ecuador y Colombia (483).

En cuanto al imperialismo:

Moda es que os viene de Francia. Aquí tenemos otra que recibimos de los Estados Unidos, y es el cansado estribillo de América para los americanos, que quita el seso a toda la gente de acá. Es moda, manía, aire natural de estos países, que se mete en el corazón y en la cabeza de cuantos aquí vivimos. Y así verás que los españoles, a los pocos años de llegar a estos climas, nos volvemos americanos y tomamos a este terruño un amor tan grande como si en él hubiéramos nacido. Nada te quiero decir de los niños que de padre español nacen aquí, pues yo tengo uno de tres años, que, apenas empezó a soltar la lengua, lo primero que aprendió fue a llamarme gachupin, gallego, patón, godo y otras perrerías con que los naturales nos motejan... (ibid., 483 ).

Fenelón apunta las consecuencias:

Que por una parte y otra, todo ha sido una función de... romanticismo... ¿Consecuencias, dices? Ninguna, como no sea ésta: que se retrasará un cuarto de siglo, lo menos, la reconciliación de España con las que fueron sus colonias. El combate de hoy ha sido, por ejemplo, el acto final de una guerra en verso... No pongas esa cara de asombro. Acá nos han mandado para que cantemos una oda en el Pacífico. Los americanos han respondido con otra canción... y he aqui todo... Ahora España envaina sus versos y se va por esos mares a la casa paterna, donde también habrá, cuando lleguemos, poesía a todo pasto $\left(5^{21}\right)$.

Esto por lo que se refiere a la historia. La novela tiene aún significado más trascendente, que expone el mismo Fenelón, después de 
informar a su amigo de que la familia Belisario "son los adeptos más rabiosos del bando antiespañol del Perú" y de que Mara se ha hecho también antiespañola, por ley natural y por ley histórica:

Yo no aseguro su antiespañolismo; pero lo presumo, porque el amor funde los sentimientos de marido y mujer. Mara siguió a Belisario deslumbrada por la poesía exuberante de América. América es ya su patria; España, clásica, rígida y enjuta, ya no lo es. ¿Qué significa esto, cándido Ansúrez? ¿Te acuerdas de nuestra primera conversación en la borda de la Numancia, cuando tomábamos carbón en San Vicente? Todo lo que tú no entendías entonces, te lo explicaba yo con una sola palabra: romanticismo. Romántico fue el amor de tu hija; románticamente te la robó Belisario; al Perú vinieron a realizar su ensueño; se han casado; son riquísimos... Todo esto quiere decir, por ejemplo, que cuando España arroja de sí el romanticismo, América lo recoge. Los ideales que desechan las madres maduras son recogidos por las hijas tiernas... España coge su rueca, y se pone a hilar el pasado; tu hija hila porvenir en rueca de oro $(489)$.

Al final del episodio Ansúrez encuentra a sus hijos y a su nieto en el Puerto de Cádiz (ibid., 536):

$Y$ en el curso de la entrañable conversación, repitió el celtíbero más de una vez este sagaz concepto.

-Lo que he visto y aprendido es que cuando a uno se le pierde el alma tiene que dar la vuelta al mundo para encontrarla.

Admirable es en esta obra la recreación del ambiente americano, que Galdós no conocía. Y admirable, sobre todo, la intuición para penetrar - al margen de pasiones políticas y nacionalismos- en el sentido de las realidades históricas.

La preocupación por América, la idea de la reconciliación de los dos mundos y de que el futuro del genio hispánico dependía de ella se manifiestan en las últimas obras con carácter casi obsesivo.

Así en El caballero encantado (19o9). Lleva como subtítulo "cuento real... inverosímil" y es una novela totalmente fantástica, con hechizos, metamorfosis, sueños, viajes y espejos mágicos. Podría decirse que es en relación con la obra de Galdós lo que el Persiles en relación con la de Cervantes. El simbolismo y el pensamiento son muy distintos, como corresponde a épocas y estilos diferentes, pero aparte de lo que ambas tienen de recapitulación poética, la trama novelesca narra "los trabajos" de la pareja simbólica. En Cervantes, Periandro-Persiles: Auristela-Sigismunda. En Galdós, Tarsis-Gil: Cintia-Pascuala. Tarsis, el caballero español arruinado, y Cintia, la heredera colombiana, se pierden y reencuentran en diversos lugares de una geografía real y fantástica a la vez. Tarsis, hechizado, vaga y 
trabaja convertido en Gil por las tierras de Soria (corazón de la Celtiberia - recordemos a Santiago Ibero soñando en nuevas conquistas por los mismos lugares) y se une con Cintia, la convertida en Pascuala, maestra de escuela, en Ágreda y en el "osario de Numancia".

El simbolismo de tal unión -España-América- se declara en varios lugares. Y en forma inconfundible en el último capítulo titulado: "Con el desencanto de Asur terminan, por hoy, estas locas aventuras hispánicas" (el subrayado es nuestro).

Reunidos finalmente, vueltos a la vida normal "el caballero español y la gentil americana", declara ésta que al hijo, que engendraron cuando eran Gil y Pascuala en la cantera de Ágreda, le ha puesto de nombre Héspero "en memoria de nuestra Madre", personificación del ideal de España, del alma de la raza.

Habla luego Cintia de las minas de plata que aparecieron en sus dominios, en Colombia. Y continúa: "Soy ahora más rica que antes. . . Tú, según dice la Madre, eres más pobre. ¿Pero qué nos importa? Nuestros bienes son comunes y entre nosotros no puede haber ya tuyo y mio.. . Haremos grandes cosas, ¿̇verdad?" Para terminar: "Descansaremos. . Siento aquí la presencia invisible de nuestra Madre, que nos manda repoblar sus estados" (VI, 349).

El significado es obvio, elemental, y una vez más debemos extrañarnos de que ni españoles ni americanos hayan prestado la menor atención a este mensaje del gran novelista, que acaso piensa con la serenidad de la vejez en sueños e ilusiones irrealizables. Está, como su personaje Santiuste en Prim, escribiendo una "Historia lógiconatural de los españoles de ambos mundos”. Lógica y natural, pero distinta de la historia real. Lo que podía y debía ser, no lo que es.

Por si aún cupiera duda de que el tema obsesiona a Galdós, recordemos que todavía en La razón de la sinrazón (1915) Alejandro de Rodas hereda la fortuna de su hermano Demetrio, fallecido en Buenos Aires. Y en la comedia Antón Caballero, que dejó inédita y refundieron los hermanos Quintero, Antón (variante de Agustín y de Pepet: "Allí en América. . he robado a la Naturaleza lo que a mi parecer no era de ella, sino mío, de todos los hombres") regresa a dar la batalla a Don Pelayo, cacique de Agramante, y sacar de sus garras a Eloísa "el ángel, el alma". Las dos obras son muy inferiores al Caballero y el tema carece en ellas de relieve. Su recuerdo demuestra, sin embargo, la persistencia de esa obsesión en el pensamiento de su autor.

La preocupación por lo americano se encuadra, en la etapa final de la creación galdosiana, en una inquietud más amplia por entender la extraña realidad histórica que es España. Inquietud que compartirán Ganivet, Unamuno, Ortega, Castro. Cada uno por su camino. El de don Benito es la fabulación novelesca, poético-histórica, la 
invención de símbolos, mitos y personajes. Éstos, en los últimos Episodios, son encarnación recreada del fondo primitivo de la raza, los Ansúrez, los Ibero. Y el sentido general del pensamiento histórico-novelesco de Galdós en este plano se aclara y refuerza si consideramos que, junto a lo americano -parte del complejo hispánico-, trata con igual propósito lo semítico: árabe-judío. Lo hallamos en Nazarín, en Almudena y, en una visión total, al historiar la guerra de África, en los episodios Aita Tettauen y Carlos VI en la Rápita. Basta a nuestros fines dejar aludido el hecho. Como en el caso de lo americano - que mira hacia el futuro-, busca en lo semítico -enraizado en el pasado medieval- lo que hay de identidad con lo español. Y por boca de su personaje Jerónimo Ansúrez lo declara explícitamente:

Pero esta guerra será dura y nos ha de costar trabajo volver con provecho y gloria. Otra cosa les digo para que se pongan en lo cierto al entender de guerras africanas, y es que el moro y el español son más hermanos de lo que parece. Quiten un poco de religión, quiten otro poco de lengua, y el parentesco y aire de familia saltan a los ojos. ¿Qué es el moro más que un español mahometano? ¿Y cuántos españoles vemos que son moros con disfraz cristiano? En lo del celo por las mujeres y en tenerlas al por mayor, allá se van los unos con los otros... (III, 220).

La prueba o contraprueba la ilustra en el episodio siguiente, Carlos VI, evocando con suprema ironía la figura medieval del Arcipreste, reencarnado en el cura guerrillero Juan Ruiz Hondón, el Vicario de Ulldecona, "patriarca y califa", con su harem, con sus múltiples amas, sobrinas y protegidas ${ }^{5}$.

Si comparamos los dos temas, el de lo americano y el de lo semítico (y otros que entrarían por modo análogo en la comprensión del complejo hispánico), vemos bien por qué el de América, de puro reflejo incidental en los medios sociales madrileños de las novelas realistas, fue adquiriendo trascendencia a medida que el arte galdosiano se encaminaba hacia la recreación total del ser de España en un mundo ya sin tiempo, en el reino de los valores, en una visión poética de la historia.

Columbia University.

ÁNGel del Río

"Cf. J. Casalduero, "Galdós y la Edad Media”, Asom, 8 (1953), núm. 2, pp. 19-23. Sobre el interés de Galdós por lo semítico y los sefardies en esta parte de su obra, cf. R. RICARD, "Sur le personnage d'Almudena dans Misericordia", BHi, 61 (1959), 12-25, y el artículo de DeNAH Lida, "De Almudena y su lenguaje", en este mismo volumen de la NRFH, pp. 297-308. 